\title{
Article
}

\section{Metacognitive beliefs as a predictor of health anxiety in a self-reporting Italian clinical sample}

Melli, Gabriele, Bailey, Robin, Carraresi, Claudia and Poli, Andrea Available at http://clok.uclan.ac.uk/21089/

Melli, Gabriele, Bailey, Robin, Carraresi, Claudia and Poli, Andrea (2018)

Metacognitive beliefs as a predictor of health anxiety in a self-reporting Italian clinical sample. Clinical Psychology \& Psychotherapy, 25 (2). pp. 263-271. ISSN 1063-3995

It is advisable to refer to the publisher's version if you intend to cite from the work. http://dx.doi.org/10.1002/cpp.2159

For more information about UCLan's research in this area go to http://www.uclan.ac.uk/researchgroups/ and search for <name of research Group>.

For information about Research generally at UCLan please go to http://www.uclan.ac.uk/research/

All outputs in CLoK are protected by Intellectual Property Rights law, including Copyright law. Copyright, IPR and Moral Rights for the works on this site are retained by the individual authors and/or other copyright owners. Terms and conditions for use of this material are defined in the policies page.

\section{CLoK}

Central Lancashire online Knowledge www.clok.uclan.ac.uk

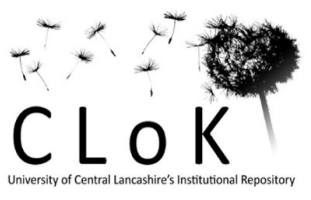




\begin{abstract}
Research has supported the specific role that anxiety sensitivity, health-related dysfunctional beliefs and metacognitive beliefs may play in the development and maintenance of health anxiety symptoms. However the role of metacognitive beliefs in health anxiety has only been explored in analogue samples. The aim of the present study was to explore for the first time the association between metacognitive beliefs and health anxiety symptoms in a sample of participants who reported having received a diagnosis of severe health anxiety (hypochondriasis) or illness anxiety disorder and test whether these beliefs are significant predictors of health anxiety after controlling for anxiety, depression, anxiety sensitivity and dysfunctional beliefs. A series of dimensional selfreport measures were administered to a large Italian sample $(N=458)$. At a bivariate level, Beliefs that Thoughts are Uncontrollable had a stronger association with health anxiety than any of the dysfunctional beliefs and anxiety sensitivity subscales. Results from hierarchical multiple regression analysis indicated that Beliefs that Thoughts are Uncontrollable predicted health anxiety symptoms over-and-above depression, general anxiety, anxiety sensitivity, and health-related dysfunctional beliefs. Despite many important limitations, this study supported the hypothesis that metacognition may have an important role in health anxiety in clinical samples.
\end{abstract}

\title{
Keywords
}

Health anxiety, metacognitive beliefs, dysfunctional beliefs, anxiety sensitivity. 


\section{$\underline{\text { Key practitioner message }}$}

- The role of metacognitive beliefs in health anxiety is underexplored

- We investigated their role over-and-above anxiety sensitivity and cognitive beliefs

- Beliefs that Thoughts are Uncontrollable seems to play the most important role

- Targeting such a metacognitive belief may result in a reduction of health anxiety 


\section{Metacognitive beliefs as a predictor of health anxiety in a self-reporting Italian clinical sample Introduction}

Health anxiety is a condition characterized by both misinterpretation of bodily sensations or physical symptoms, and by obsessional ideas that one has (or will develop) a serious illness (Abramowitz, Olatunji, \& Deacon, 2007b; Taylor \& Asmundson, 2004). Health anxiety can result in high levels of psychological distress and functional impairment for the individual and also result in an overutilization of medical resources (Creed \& Barsky, 2004; Lee, Creed, Ma, \& Leung, 2015).

Health anxiety in its severe form has been previously subsumed under the diagnosis of hypochondriasis (DSM-IV-TR; American Psychiatric Association [APA], 2000) and more recently in DSM-5 (APA, 2013) as illness anxiety disorder, however both these diagnostic entities have their limitations. Hypochodriasis in DSM-IV has been challenged as being a narrowly descriptive, arbitrary and pejorative definition specifically for health-anxious patients who present in primary care settings (Bailer et al., 2016). Equally the newly defined Illness Anxiety Disorder has been identified as being inconsistent and contradictory to DSM-IV's criteria for hypochondriasis (Starcevic, 2014), with as low as $36 \%$ of people with a diagnosis of illness anxiety disorder meeting the diagnosis of hypochondriasis (Newby et al., 2017). Contemporary theories have conceptualized the condition of health anxiety as a dimensional as opposed to a psychiatric construct, existing on a continuum from mild to severe (Bailer et al., 2016; Ferguson, 2009; Longley et al., 2010; Williams, 2004). As health anxiety is considered a dimensional rather than a categorical construct (i.e.

presence or absence of a diagnosis), a dimensional assessment has been considered important in accurately capturing the occurrence and severity of this presentation. Self-report measures have been commonly used clinically and within research settings as a means to assess and screen health anxiety.

Over the past thirty years there has been a proliferation of different theories which have aimed to provide evidence for what specific psychological variables contribute to this disorder. One of the 
earliest theories has been posited by research carried out by the original Oxford cognitive therapy group, which was informed by Beck's schema theory (1976). Arising from Clark's original model of panic disorder (Clark, 1986), health anxiety was also conceived to be driven and maintained by an individual's specific cognitive appraisals, in particular catastrophic misinterpretations of bodily symptoms (Salkovskis \& Warwick, 1986; Warwick \& Salkovskis, 1990). Since the development of this theory there has been a plethora of research that tends to support the idea that these specific cognitive appraisals are strongly associated with health anxiety (e.g., Marcus, Gurley, Marchi, \& Bauer, 2007; Norris \& Marcus, 2014). The cognitive model further posits that health anxious individual's tendency to misinterpret bodily symptoms is driven and guided by specific underlying dysfunctional beliefs about illness and health (Salkovskis, 1996). In particular, four specific healthrelated dysfunctional beliefs are given centrality in the model: (a) likelihood of experiencing a health problem; (b) awfulness of experiencing a health problem; (c) inability to cope with an experienced health problem; (d) inadequacy of medical resources to treat an experienced health problem (Salkovskis \& Warwick, 2001). To date a small number of cross sectional studies in nonclinical samples have demonstrated that these dysfunctional beliefs are significantly associated with health anxiety (e.g., Fergus, 2014; Hadjistavpopulos et al., 2012).

Another specific variable that has recently been associated with health anxiety is anxiety sensitivity. This particular construct relates to an individual's fear of the social, cognitive and physical effects of anxiety itself (Reiss, 1987). Evidence exists that anxiety sensitivity has a role in health anxiety, in both clinical and non-clinical samples (e.g., Abramowitz et al., 2007b; Abramowitz, Deacon, \& Valentiner, 2007a; Otto, Demopulos, McLean, Pollac, \& Fava, 1998) and correlations have been found to be significant, when controlling for negative affect and intolerance of uncertainty (Norton, Sexton, Walker, \& Norton, 2005; Sexton, Norton, Walker, \& Norton, 2003). Although anxiety sensitivity has been found to be a significant predictor of health anxiety (Boston, 2013; Gerolimatos \& Edelstein, 2012), research indicates that it does not completely explain all of 
the variance in health anxiety symptoms (Abramowitz et al., 2007b; Deacon \& Abramowitz, 2008; Watt \& Stewart, 2000).

A newer approach to conceptualizing the development and maintenance of health anxiety has been based upon a metacognitive theory of psychological disorder (Wells \& Matthews, 1994, 1996). According to metacognitive theory, it is an individual's beliefs about their thinking (metacognitive beliefs) which are of more importance than the actual content of their thoughts (Wells, 2009). More specifically people hold both positive beliefs about the benefits of extended thinking such as "I must worry in order to be prepared" and negative beliefs about the consequences of extended thinking such as "I cannot control my thoughts" (Wells, 2004), which can lead to unhelpful responses such as worry and rumination. These responses in turn contribute to the development and persistence of psychological disorder. Thus the metacognitive model proposes that cognitions are controlled by metacognitions and it is these metacognitive beliefs that are reponsible for guiding how a person responds to their thoughts (Wells, 2009). Consistent with this model, several cross sectional studies in non-clinical samples have demonstrated a strong association between metacognition and health anxiety. Bailey and Wells (2013) found that metacognitive beliefs explained a significant amount of variance in health anxiety symptoms over and above other variables associated with health anxiety, such as somatosensory amplification, catastrophic misinterpretations and neuroticism. In particular, the results revealed three independent metacognitive predictors of health anxiety: "negative metacognitive beliefs about uncontrollability and danger", "beliefs about the need for thought control", and "cognitive confidence" (Bailey \& Wells, 2013). In a further study evaluating both the cognitive and metacognitive model, Bailey and Wells (2016a) explored the relative contribution of dysfunctional beliefs and metacognitive beliefs in predicting health anxiety. Metacognitive beliefs emerged as having a stronger association with health anxiety than dysfunctional beliefs. Additionally, results of the regression analysis revealed that after controlling for neuroticism and dysfunctional beliefs, metacognitive beliefs explained a significant and large amount of the variance (47\%) in health anxiety. Bailey and Wells (2015a) also 
found that metacognitive beliefs moderate the relationship between catastrophic misinterpretation of bodily symptoms and health anxiety showing that catastrophic misinterpretation alone did not predict health anxiety without the input of metacognition. More recently, the same authors (Bailey \& Wells, 2016b) specifically tested the prospective relationship between all variables considered important in predicting health anxiety, such as, catastrophic misinterpretations, dysfunctional illness beliefs, somatosensory amplification, neuroticism and metacognitive beliefs. In this study, metacognitive beliefs emerged as the only independent and significant prospective predictors of health anxiety. Additionally, it emerged that metacognitive beliefs also prospectively moderated the relationship between catastrophic misinterpretation and health anxiety, again indicating that the causal relationship between cognition and health anxiety is dependent upon metacognition. Melli, Carraresi, Poli and Bailey (2016), exploring the association between metacognitive beliefs and health anxiety in a large Italian community sample, replicated previous findings and found a significant correlation between these variables. Furthermore, metacognitive beliefs about uncontrollability and interference of illness thoughts were found to be significant predictors of health anxiety symptoms, after controlling for anxiety, depression, dysfunctional cognitions and anxiety sensitivity. This study also identified that the relationship between anxiety sensitivity and health anxiety was moderated by metacognitive beliefs, further supporting the importance of metacognition in health anxiety.

In sum, although the studies discussed have identified that metacognitive beliefs may be an important variable in both the development and maintenance of health anxiety, none of these studies have used clinical participants. Hence, the aim of the present study was to further explore the association between metacognitive beliefs and health anxiety symptoms using a large Italian selfreporting clinical sample, trying to replicate the findings of previous studies (e.g., Bailey \& Wells, 2016a; Melli et al., 2016). In particular, it was hypothesized that: (a) health anxiety would show a significant correlation with metacognitive beliefs; (b) metacognitive beliefs would be a significant 
predictor of health anxiety after controlling for anxiety, depression, anxiety sensitivity and dysfunctional cognitions.

\section{Methods}

\section{Participants}

A sample of people who self-reported that they had received a diagnosis of hypochondriasis or illness anxiety disorder by a qualified clinician (licensed psychiatrist or clinical psychologist) was collected through distributing study information to health anxiety and hypochondriasis support groups and through placing an advertisement on a well-known website about mental health disorders including health anxiety. Information about the study was also given to mental health practitioners and distributed at an Italian conference for mental health workers with the request to be circulated to their patients.

Four hundred and fifty-eight participants were recruited (mean age $=33.97, S D=12.18$, range: $16-81,67.0 \%$ female). All the selected participants reported a qualitative description of their symptoms that was thoroughly reviewed in order to ascertain that it met with the diagnostic criteria for hypochondriasis or illness anxiety disorder. Moreover, the majority (82\%) scored above the cutscores (Melli, Coradeschi, \& Smurra, 2007) on the Health Anxiety Questionnaire (HAQ; see below), indicating a sample very likely to suffer from illness anxiety disorder or severe health anxiety.

$52.2 \%$ of the participants had a medium level of education (12-13 years, high school degree), $28.2 \%$ had a high level (16 or more years, bachelor's degree or Ph.D.) and the remaining 19.6\% had a low level (eight or less years, primary or secondary school license). Most of the participants were employed (50.6\%), $23.6 \%$ were undergraduate university students, and the remaining $25.8 \%$ were homemakers, unemployed, or retired. Most were married or cohabiting (51.5\%), while $43.4 \%$ were single, $5.1 \%$ were divorced, widows or widowers.

\section{Measures}


Health Anxiety Questionnaire (HAQ). This is 21-item self-report measure that assesses the severity of health anxiety. It consists of four sub-scales, which measure health worry and preoccupation, fear of illness and death, reassurance-seeking behavior and interference with life. The original version of the HAQ (Lucock \& Morley, 1996) has shown good psychometric properties, and its Italian version (Melli et al., 2007) has shown adequate internal consistency ( $\alpha>$ .77 for all subscales), temporal stability $(r=.89)$ and construct validity. Given that we were interested in assessing the global severity of health anxiety, in the present study only the total score was computed.

Depression Anxiety Stress Scales-21 (DAAS-21). The DASS (Lovibond \& Lovibond, 1995) is a self-report questionnaire listing negative emotional symptoms and is divided into three subscales measuring depression, anxiety and stress. In this study we used the short version of the DASS (Antony, Bieling, Cox, Enns, \& Swinson, 1998; Clara, Cox, \& Enns, 2001), which contains 21 items, 7 items for each scale. Participants rated how often a particular symptom was experienced in the past week. The original DAAS-21 has shown good psychometric properties, and its Italian version (Bottesi et al., 2015) has replicated the three-factor structure of the original version, and has shown good internal consistency ( $\alpha$ in the range .74-.92), test-retest reliability ( $r$ in the range .64.74), and construct validity.

Anxiety Sensitivity Index-3 (ASI-3). This is an 18-item self-report inventory that assesses the degree to which the individual fears the potential negative consequences of anxiety-related symptoms and sensations (e.g., "It scares me when my heartbeats fast"). The ASI-3 consists of a single higher-order factor and three lower order factors (physical concerns, cognitive concerns, social concerns). Statement choices are scored from 0 ('very little') to 4 ('very much'). The original ASI-3 (Taylor et al., 2007) has shown good psychometric properties, and its Italian version has shown good internal consistency ( $\alpha>.77$ for all subscales), adequate temporal stability (ICC > .75 for all scales), and good construct validity (Ghisi et al., 2016; Pozza \& Dèttore, 2015). 
Health Cognition Questionnaire (HCQ). This is a 21-item self-report measure that assesses Salkovskis and Warwick's (2001) four health-related dysfunctional beliefs. The four HCQ scales are as follows: Likelihood of Illness; Awfulness of Illness; Difficulty Coping; and Medical Services Inadequacy. The original version of the HCQ (Hadjistavropoulos et al., 2012) has shown good psychometric properties, and its Italian version (Melli, Gelli, \& Carraresi, submitted) has shown good internal consistency ( $\alpha>.82$ for all subscales), adequate temporal stability $(r>.65$ for all scales), and good construct validity.

Metacognitions Questionnaire-Health Anxiety (MCQ-HA). This is a 14-item measure of health anxiety related metacognitions, based on the original Metacognition Questionnaire (MCQ: Cartwright-Hatton \& Wells, 1997). The measure consists of three subscales: "Beliefs that Thoughts cause Illness” (MCQ-HAC; e.g., 'Thinking negatively can increase my chances of disease'); "Beliefs about Biased Thinking” (MCQ-HAB; e.g., 'I will be punished for thinking I am in good health'); and "Beliefs that Thoughts are Uncontrollable" (MCQ-HAU; e.g., 'I have no control over thinking about my health'). The factor structure has been supported through exploratory and confirmatory factor analyses and the measure has demonstrated excellent reliability and adequate discriminant, convergent and incremental validity (Bailey \& Wells, 2015b). Though a formal Italian validation of this measure does not exist, the original scale was first translated into Italian by two independent translators, who were not members of the study team. The final Italian version was derived from the combination of these two independent translations in liasion with the study investigators. The Italian version was then back translated into English by a native English speaker who are also fluent in Italian, who had not read the original English version of MCQ-HA. Backtranslation in English was then compared with the original English version by the study investigators, and the final Italian version of the MCQ-HA was agreed. The factor structure of the measure was tested in the present sample through confirmatory factor analysis (CFA) using Mplus 6.1, Robust Maximum Likelihood (MLR) estimator. The goodness-of-fit indices were almost optimal $(\mathrm{RMSEA}=.06 ; \mathrm{CFI}=.95 ; \mathrm{TLI}=.94 ;$ Marsh, Hau, \& Wen, 2004). Cronbach's alpha 
showed adequate values on the measures total and all subscales $(\alpha \geq .77)$. Mean inter-item correlations were higher than .40.and all corrected item-total correlations were higher than .49. In no cases were the alpha-if-item-deleted higher than the computed alpha, suggesting that all items contribute to the internal consistency of the subscales.

\section{Procedures}

The questionnaires were made available online using a secure web-based survey programme (SurveyMonkey). Questionnaires were administered in counterbalanced fashion to control for order and sequence effects, and batteries took between 15 and 25 minutes to complete. All participants volunteered to take part in the study after being presented with a detailed description of the procedure and were treated in accordance with the Ethical Principles of Psychologists and Code of Conduct (American Psychological Association, 2010). No external incentives were offered for participating in this study.

\section{Statistical analysis}

To test the hypotheses about the relationships between metacognition and health anxiety symptoms, Pearson zero-order correlations between the HAQ, the HCQ, and MCQ-HA subscales were examined. A hierarchical regression analysis was then conducted to test the robustness of these associations and determine whether metacognitive beliefs contribute to the prediction of health anxiety symptoms above and beyond depression, anxiety, stress, anxiety sensitivity and dysfunctional beliefs. In the first step of the regression, DASS-21 subscale scores were entered in order to control for confounding variables. In the second step, ASI-3 subscale scores were entered to examine whether anxiety sensitivity dimensions increased the proportion of explained variance. In the third step, the four subscales of the HCQ were entered to explore their role in predicting health anxiety symptoms. In the fourth step, the three subscales of the MCQ-HA were entered to test the hypothesis that metacognitive beliefs had a predictive role above and beyond all the other variables.

\section{Results}




\section{Descriptive statistics}

Mean scores, standard deviations, ranges, skewness, kurtosis and Cronbach's alphas for each measure are presented in Table 1. The sample mean scores on all measures fell within the normal range reported in other Italian clinical samples (e.g., Bottesi et al., 2015; Pozza \& Dèttore, 2015). Internal consistency estimates for all measures were good or better (Cronbach's alphas $\geq .77$ ). None of the indices of univariate skewness and kurtosis were sufficiently high so as to preclude the planned analyses (Tabachnick \& Fidell, 2013).

\section{Zero-order correlations}

As shown in Table 1, there was a large correlation between HAQ and ASI-3-Phisical $(r=$ $.56)$, between the HAQ and the HCQ-Awfulness of Illness $(r=.52)$, and between the HAQ and the MCQ-HA-Beliefs that Thoughts are Uncontrollable $(r=.61)$. The HAQ also showed a moderate correlation with the ASI-3 Cognitive, the HCQ-Likelihood of Illness, the HCQ-Difficulty Coping, and the other two MCQ-HA subscales. In particular, the association of HAQ with MCQ-HA-Beliefs that Thoughts are Uncontrollable was significantly greater than those with HCQ-L $(Z=3.20 ; p<$ $.01)$ and HCQ-A $(Z=2.54 ; p<.01)$.

\section{[Table 1]}

\section{Hierarchical linear regression analysis}

Variance inflation factor (VIF) was calculated for the predictors and was within normal ranges for all of them $(\mathrm{VIF}=1.12-2.02)$, indicating that multicollinearity was not a problem (Menard, 1995). Further examination of the data also indicated that the assumptions of linearity and homoscedasticity were met.

Results of the regression analysis are presented in Table 2. In the first step of the regression analysis predicting HAQ, the DASS-21 scores explained a significant proportion of variance $\left(R^{2}=\right.$ $.27 ; p<.001)$. In the second step, adding the ASI-3 subscale scores, the variance explained significantly increased $\left(R^{2}\right.$ change $\left.=.16 ; p<.001\right)$ and both the ASI-P $(\beta=.41 ; p<.001)$ and the ASI-C $(\beta=.13 ; p<.01)$ emerged as significant predictors. In the third step, adding the HCQ 
subscale scores, the variance explained significantly increased $\left(R^{2}\right.$ change $\left.=.13 ; p<.001\right)$. In particular, in this model all the HCQ subscales - except for the HCQ-Medical Services Inadequacy emerged as significant predictors together with the DASS-21 and ASI-3-Phisical. In the fourth step, adding the MCQ-HA subscale scores, the variance explained significantly increased $\left(R^{2}\right.$ change $=$ $.05 ; p<.001)$. In particular, the MCQ-HA-U emerged as the most important predictor $(\beta=.25 ; p<$ .001) after the ASI-3 Physical, while the HCQ-L, the HCQ-A, and the HCQ-C showed a very low, although significant, predicting role. None of the other MCQ-HA factors were found to significantly add to the prediction of HAQ scores. The final model accounted for $61 \%$ of the variance and was statistically significant $\left(R^{2}=.61 ; p<.001\right)$.

[Table 2]

\section{Discussion}

The aim of the current study was to investigate the role of metacognitive beliefs in health anxiety and to test whether these beliefs are significant predictors of the disorder whilst controlling for depression, anxiety, anxiety sensitivity symptoms and dysfunctional beliefs in a self-reporting clinical sample.

In line with previous cross-sectional studies (e.g. Abramowitz, et al., 2007a, 2007b; Hadjistavpopulos, et al., 2012; Melli, et al., 2016) all variables investigated in this study were significantly associated with health anxiety, except for the dysfunctional belief "HCQ-M = HCQMedical Services Inadequacy". This particular dysfunctional belief has also been shown not to be significantly correlated with health anxiety in other studies (Bailey \& Wells, 2016a, 2016b). As expected, the strongest association with health anxiety was the metacognitive variable "Beliefs that Thoughts are Uncontrollable (MCQ HA-U)" supporting our primary hypothesis that health anxiety would be significantly correlated with metacognition in a self reporting clinical population. This finding supports a range of previous studies (e.g., Bailey \& Wells, 2013; Fergus \& Bardeen, 2017; Melli et al., 2016) which have demonstrated that metacognitive beliefs are strongly associated with health anxiety using non-clinical samples. 
A hierarchical regression analysis was conducted to further analyze the robustness of the relationship between metacognitive beliefs and health anxiety and to determine specifically if metacognition is a predictor of health anxiety after controlling for other independent health anxiety variables.

As anticipated, metacognitive beliefs that thoughts are uncontrollable significantly predicted health anxiety symptoms over and above all other variables. This particular metacognitive belief has consistently emerged as a predictor of health anxiety in every study where it has been evaluated (e.g. Bailey \& Wells, 2013, 2015a, 2016a; Melli, et al., 2016), and the findings in this sample further support its importance. The magnitude of variance explained by the metacognitive variables $\left(R^{2}\right.$ change $\left.=.05 ; p<.001\right)$ was exactly the same as the variance explained by metacognitions in a non-clinical sample in a previous study (Melli, et al., 2016). The subscale metacognitive beliefs that thoughts are uncontrollable also emerged as the second most important variable after anxiety sensitivity physical, and had the same beta value $(\beta=.25 ; \mathrm{p}<.001)$ as in the previous non-clinical study (Melli et al., 2016).

This is an interesting finding as the metacognitive measure used in this study was the MCQHA (Bailey \& Wells, 2015b), while the metacognitive measure used in Melli et al. (2016) was the Metacognition about Health Anxiety (MCHA; Bouman \& Meijer, 1999). The similar findings in both studies are consistent with Marcus et al. (2007) who found that elevated health anxiety and health anxious beliefs were similar in both clinical and non-clinical samples. Based on the findings in this study metacognitive beliefs may also be equally important in both self-reporting clinical and non-clinical health anxious populations.

The other subscales of the MCQ-HA were not found to be significant predictors of health anxiety despite their initial correlation. This is inconsistent with other studies which have shown that Beliefs about Biased Thinking, and Beliefs that Thoughts can Cause Illness emerged as independent significant predictors of health anxiety when controlling for other variables associated with health anxiety (Bailey \& Wells, 2016a). As health anxiety has been conceptualized as a 
dimensional as opposed to a psychiatric construct, existing on a continuum from mild to severe (e.g. Ferguson, 2009; Longley et al., 2010), it may be "beliefs about biased thinking" and "beliefs that thoughts cause illness" maybe more prevalent in milder non-clinical cases of health anxiety, than in severe clinical cases. It has been noted that positive metacognitive beliefs about worry, e.g., "beliefs about bias thinking" are often considered non-threatening and considered common in the general population (Wells, 2009). Beliefs about the uncontrollability of thinking however are considered universally problematic in all disorders (see, Bailey \& Wells, 2016a) as they directly link to threatening interpretations of mental events and therefore when present may cause elevated health anxiety in both clinical and non-clinical cases.

Anxiety sensitivity physical was also found to be the strongest significant predictor of health anxiety which corroborates other previous findings which have implicated its significance in health anxiety (e.g., Abramowitz et al., 2007a, 2007b; Otto et al., 1998). Additionally, three of the dysfunctional beliefs made weak but independent contributions to health anxiety in the final equation, again supporting previous findings (Fergus, 2014; Hadjistavpopulos et al., 2012).

How might the significance of anxiety sensitivity and dysfunctional beliefs impact on the metacognitive model? Firstly, anxiety sensitivity physical can be explained as a trigger for worry and rumination, and it is these processes which have been conceptualised as instrumental in the maintenance of health anxiety according to the metacognitive model. For example, "When my stomach is upset, I worry that I might be seriously ill” can lead an individual into excessive health worry if they have high levels of beliefs regarding the uncontrollability of worry. A number of studies have indeed demonstrated that the relationship between beliefs about somatic symptoms and health anxiety may well be dependent upon metacognitive beliefs (Bailey \& Wells, 2015a, 2016b). Secondly, dysfunctional beliefs in the metacognitive model can be considered the output or conclusions of running these worry and rumination processes. For example, "I am not sure that I can handle any serious health problem that I might develop in the future" may be the product of extended thinking (worry) and becomes more problematic for the individual when moderated by 
beliefs regarding the uncontrollability of worry (Bailey \& Wells, 2015a, 2016b). Furthermore, health anxiety has been associated with alterations in somatosensory information processing, in particular with the processing of information originating within the body (i.e., interoception; Sherrington, 1948). Three hierarchical layers of interoceptive dimensions have been recently proposed by Garfinkel and Critchley (2013): the first layer, interoceptive sensibility, represents a trait-like proneness to focus on bodily processes; the second layer, interoceptive sensitivity, refers to the ability to accurately detect bodily sensations; the top layer represents interoceptive awareness, i.e., the level of metacognitive awareness of interoceptive sensitivity and, in particular, the level of being aware/confident that one is perceiving one's own bodily sensations accurately. It has recently been demonstrated that, after controlling for comorbid anxiety disorders, there was no evidence for increased interoceptive sensitivity in patients with clinically relevant health anxiety with respect to healthy controls (Krautwurst, Gerlach, \& Witthöft, 2016). Accordingly, the third layer encompassing metacognitive awareness level may play the most relevant role in the development and maintenance of clinical health anxiety.

In essence, the metacognitive model presents an explanation of health anxiety that is different from cognitive models, in that health anxiety is seen as resulting more from extended and repetitive negative thinking about illness i.e. worry/rumination rather than from the belief that one is ill, i.e. dysfunctional beliefs and anxiety sensitivity.

If metacognition is an important variable that gives rise to the maintenance of health anxiety in a self-reporting clinical sample, this has potential implications for mechanisms of change in therapy. To date, a number of studies have demonstrated that targeting metacognitive beliefs in clinical samples has resulted in a reduction of health anxious symptomology. Using the attention training technique (ATT) as a standalone metacognitive intervention, Papergeoriou \& Wells (1998) treated 3 patients diagnosed with DSM-IV hypochondriasis. ATT is proposed to work by strengthening an individual's attentional flexibility as a means of interrupting the worry, rumination and threat monitoring, thus strengthening metacognitive plans for cognitive control (Wells, 2009). 
In this A-B-A case series all patients reached clinical significant changes on measures of cognition, behavioural responses (e.g. reassurance seeking), affect and bodily focused attention, at post treatment and six month follow-up. Additionally, none of the patients met the diagnostic criteria for hypochondriasis at post-treatment and at follow-up. In another case series utilising a full metacognitive therapy (MCT) treatment protocol, Bailey \& Wells (2014) treated 4 patients diagnosed with DSM-IV hypochondriasis. All patients demonstrated large and clinically meaningful improvements in specific hypochondriacal symptoms and more general negative affect measures. Treatment gains were maintained at 6-month follow-up. Substantial changes were also observed in metacognitive beliefs.

There are a number of major limitations to the current study. First, although the participants self-reported that they had received a diagnosis of hypochondriasis or illness anxiety disorder by a qualified clinician, no structured clinical interview was carried out to identify a formal diagnosis and different clinicians might have applied different criteria in order to perform diagnoses. Therefore, the sample may not have been representative of the clinical population and we cannot conclusively state they would meet clinical diagnoses. This may limit the generalizability of the findings which need replications in further studies using clinical participants with a formal diagnosis of illness anxiety disorder. Second, though goodness-of-fit indices of the reported confirmatory factor analysis and reliability indices were more than adequate in this sample, the measure of metacognition (MCQ-HA) used in this study has not been subjected to a thorough and detailed validation study based on its translation from English to Italian. Further studies need to assess the psychometric properties of the Italian version of this measure. Third, although regression analysis allowed to speculate about the direction of the relationships between the variables the current study was cross-sectional and the temporal dynamics of the interactions cannot be defined. Alternative temporal orders have not been ruled out and it is also possible that the identified relationships are bi-directional in nature. Future studies with clinical populations could track these beliefs during treatment to see whether changes in these beliefs precede any reduction in symptoms. 
Despite these limitations, the findings of this study indicate that metacognitive beliefs may be an important variable in the maintenance of health anxiety and provide further support for the metacognitive model. 


\section{References}

Abramowitz, J. S., Deacon, B. J., \& Valentiner, D. P. (2007a). The Short Health Anxiety Inventory: Psychometric Properties and Construct Validity in a Non-clinical Sample. Cognitive Therapy and Research, 31(6), 871-883. http://doi.org/10.1007/s10608-006-9058-1

Abramowitz, J. S., Olatunji, B. O., \& Deacon, B. J. (2007b). Health Anxiety, Hypochondriasis, and the Anxiety Disorders. Behavior Therapy, 38(1), 86-94. http://doi.org/10.1016/j.beth.2006.05.001

American Psychiatric Association. (2000). Diagnostic and statistical manual of mental disorders text revision (4th ed.). Washington, DC: American Psychiatric Association.

American Psychiatric Association. (2013). Diagnostic and statistical manual of mental disorders (5th ed.). Arlington, VA: American Psychiatric Publishing.

American Psychological Association. (2010). Ethical Principles of Psychologists and Code of Conduct. Retrieved from http://www.apa.org/ethics/code/principles.pdf

Antony, M. M., Bieling, P. J., Cox, B. J., Enns, M. W., \& Swinson, R. P. (1998). Psychometric properties of the 42-item and 21-item versions of the Depression Anxiety Stress Scales in clinical groups and a community sample. Psychological Assessment, 10(2), 176-181. http://doi.org/10.1037/1040-3590.10.2.176

Bailer, J., Kerstner, T., Witthöft, M., Diener, C., Mier, D., \& Rist, F. (2016). Health anxiety and hypochondriasis in the light of DSM-5. Anxiety, Stress, \& Coping, 29(2), 219-239.

Bailey, R., \& Wells, A. (2013). Does metacognition make a unique contribution to health anxiety when controlling for neuroticism, illness cognition, and somatosensory amplification? Journal of Cognitive Psychotherapy, 27(4), 327-337. http://doi.org/10.1891/0889-8391.27.4.327

Bailey, R., \& Wells, A. (2014). Metacognitive Therapy in the Treatment of Hypochondriasis: A Systematic Case Series. Cognitive Therapy and Research, 38(5), 541-550. http://doi.org/10.1007/s10608-014-9615-y

Bailey, R., \& Wells, A. (2015a). Metacognitive beliefs moderate the relationship between 
catastrophic misinterpretation and health anxiety. Journal of Anxiety Disorders, 34, 8-14. http://doi.org/10.1016/j.janxdis.2015.05.005

Bailey, R., \& Wells, A. (2015b). Development and initial validation of a measure of metacognitive beliefs in health anxiety: The MCQ-HA. Psychiatry Research, 230(3), 871-877. http://doi.org/10.1016/j.psychres.2015.11.035

Bailey, R., \& Wells, A. (2016a). The contribution of metacognitive beliefs and dysfunctional illness beliefs in predicting health anxiety: An evaluation of the metacognitive versus the cognitive models. Clinical Psychologist, 20(3), 129-137. http://doi.org/10.1111/cp.12078

Bailey, R., \& Wells, A. (2016b). Is metacognition a causal moderator of the relationship between catastrophic misinterpretation and health anxiety? A prospective study. Behaviour Research and Therapy, 78, 43-50. http://doi.org/10.1016/j.brat.2016.01.002

Beck, A. T. (1976). Cognitive therapy and the emotional disorders. International Universities Press.

Boston, A. F. (2013). Health anxiety and older adults: A cross sectional study comparing predictors of health anxiety between an older and younger cohort. Massey University. Retrieved from http://hdl.handle.net/10179/4755

Bottesi, G., Ghisi, M., Altoè, G., Conforti, E., Melli, G., \& Sica, C. (2015). The Italian version of the Depression Anxiety Stress Scales-21: Factor structure and psychometric properties on community and clinical samples. Comprehensive Psychiatry, 60, 170-181. http://doi.org/10.1016/j.comppsych.2015.04.005

Bouman, T. K., \& Meijer, K. J. (1999). A Preliminary Study of Worry and Metacognitions in Hypochondriasis. Clinical Psychology and Psychotherapy, 6(2), 96-101. http://doi.org/10.1002/(SICI)1099-0879(199905)6:2<96::AID-CPP190>3.0.CO;2-G

Cartwright-Hatton, S., \& Wells, A. (1997). Beliefs about Worry and Intrusions: The MetaCognitions Questionnaire and its Correlates. Journal of Anxiety Disorders, 11(3), 279-296. http://doi.org/10.1016/S0887-6185(97)00011-X

Clara, I. P., Cox, B. J., \& Enns, M. W. (2001). Confirmatory Factor Analysis of the Depression- 
Anxiety-Stress Scales in Depressed and Anxious Patients. Journal of Psychopathology and Behavioral Assessment, 23(1), 61-67. http://doi.org/10.1023/A:1011095624717

Clark, D. M. (1986). A cognitive approach to panic. Behaviour Research and Therapy, 24(4), 461470. http://doi.org/10.1016/0005-7967(86)90011-2

Creed, F., \& Barsky, A. (2004). A systematic review of the epidemiology of somatisation disorder and hypochondriasis. Journal of Psychosomatic Research. http://doi.org/10.1016/S00223999(03)00622-6

Deacon, B., \& Abramowitz, J. S. (2008). Is Hypochondriasis Related to Obsessive-Compulsive Disorder, Panic Disorder, or Both? An Empirical Evaluation. Journal of Cognitive Psychotherapy, 22(2), 115-127. http://doi.org/10.1891/0889-8391.22.2.115

Fergus, T. A. (2014). Health-Related Dysfunctional Beliefs and Health Anxiety: Further Evidence of Cognitive Specificity. Journal of Clinical Psychology, 70(3), 248-259. http://doi.org/10.1002/jclp.22012

Fergus, T. A., \& Bardeen, J. R. (2017). The Metacognitions Questionnaire-30. Assessment, 1073191116685807. http://doi.org/10.1177/1073191116685807

Ferguson, E. (2009). A taxometric analysis of health anxiety. Psychological Medicine, 39, 277-285.

Garfinkel, S. N., \& Critchley, H. D. (2013). Interoception, emotion and brain: new insights link internal physiology to social behaviour. Commentary on: "Anterior insular cortex mediates bodily sensibility and social anxiety" by Terasawa et al. (2012). Social Cognitive and Affective Neuroscience. http://doi.org/10.1093/scan/nss140

Gerolimatos, L. A., \& Edelstein, B. A. (2012). Predictors of health anxiety among older and young adults. International Psychogeriatrics, 24(12), 1998-2008. http://doi.org/10.1017/S1041610212001329

Ghisi, M., Bottesi, G., Altoè, G., Razzetti, E., Melli, G., \& Sica, C. (2016). Factor Structure and Psychometric Properties of the Anxiety Sensitivity Index-3 in an Italian Community Sample. Frontiers in Psychology, 7(160), 1-13. http://doi.org/10.3389/fpsyg.2016.00160 
Hadjistavropoulos, H. D., Janzen, J. A., Kehler, M. D., Leclerc, J. A., Sharpe, D., \& BourgaultFagnou, M. D. (2012). Core cognitions related to health anxiety in self-reported medical and non-medical samples. Journal of Behavioral Medicine, 35(2), 167-178.

http://doi.org/10.1007/s10865-011-9339-3

Krautwurst, S., Gerlach, A. L., \& Witthöft, M. (2016). Interoception in pathological health anxiety. Journal of Abnormal Psychology, 125(8), 1179-1184. http://doi.org/10.1037/abn0000210

Lee, S., Creed, F. H., Ma, Y. L., \& Leung, C. M. C. (2015). Somatic symptom burden and health anxiety in the population and their correlates. Journal of Psychosomatic Research, 78(1), 71-76. http://doi.org/10.1016/j.jpsychores.2014.11.012

Longley, S. L., Broman-Folks, J. J., Calamari, J. E., Noyes, R., Wade, M., \& Rolando, C. M. (2010). A taxometric study of hypochondriasis symptoms. Behaviour Therapy, 41(4):505-14.

Lovibond, S. H., \& Lovibond, P. F. (1995). Manual for the Depression Anxiety Stress Scales (2nd ed.). Sydney, Australia: Psychological Foundation.

Lucock, M., \& Morley, S. (1996). The health anxiety questionnaire. British Journal of Health Psychology, 1, 137-150. http://doi.org/10.1111/j.2044-8287.1996.tb00498.x

Marcus, D. K., Gurley, J. R., Marchi, M. M., \& Bauer, C. (2007). Cognitive and perceptual variables in hypochondriasis and health anxiety: A systematic review. Clinical Psychology Review, 27(2), 127-139. http://doi.org/10.1016/j.cpr.2006.09.003

Marsh, H. W., Hau, K. T., \& Wen, Z. (2004). In search of golden rules: Comment on hypothesis testing approaches to setting cutoff values for fit indexes and dangers in overgeneralising $\mathrm{Hu} \&$ Bentler's (1999) findings. Structural Equation Modeling, 11, 320-341.

Melli, G., Carraresi, C., Poli, A., \& Bailey, R. (2016). The role of metacognitive beliefs in health anxiety. Personality and Individual Differences, 89, 80-85. http://doi.org/10.1016/j.paid.2015.10.006

Melli, G., Coradeschi, D., \& Smurra, R. (2007). The Italian version of Health Anxiety Questionnaire: reliability and factorial analysis. Psicoterapia Cognitiva E Comportamentale, 13, 
$37-48$.

Melli, G., Gelli, S., \& Carraresi, C. (submitted). The Italian versions of the Health Cognition Questionnaire (HCQ) and the Metacognition about Health Anxiety (MCHA): Psychometric properties and factor structures, Submitted for publication.

Menard, S. (1995). Applied logistic regression analysis. Sage University paper series on quantitative applications in the social sciences, 07-106. Thousands Oaks, CA: Sage.

Newby, J. M., Hobbs, M. J., Mahoney, A. E., Wong, S. K., \& Andrews, G. (2017). DSM-5 illness anxiety disorder and somatic symptom disorder: Comorbidity, correlates, and overlap with DSM-IV hypochondriasis. Journal of Psychosomatic Research, 101, 31-37.

Norris, A. L., \& Marcus, D. K. (2014). Cognition in Health Anxiety and Hypochondriasis : Recent Advances. Current Psychiatry Reviews, 10, 44-49.

http://doi.org/10.2174/1573400509666131119004151

Norton, P. J., Sexton, K. A., Walker, J. R., \& Norton, G. R. (2005). Hierarchical Model of Vulnerabilities for Anxiety: Replication and Extension with a Clinical Sample. Cognitive Behaviour Therapy, 34(1), 50-63. http://doi.org/10.1080/16506070410005401

Otto, M. W., Demopulos, C. M., McLean, N. E., Pollack, M. H., \& Fava, M. (1998). Additional Findings on the Association Between Anxiety Sensitivity and Hypochondriacal Concerns: Examination of Patients with Major Depression. Journal of Anxiety Disorders, 12(3), 225-232. http://doi.org/10.1016/S0887-6185(98)00011-5

Papageorgiou, C., \& Wells, A. (1998). Effects of attention training on hypochondriasis: a brief case series. Psychological Medicine, 28(1), 193-200.

Pozza, A., \& Dèttore, D. (2015). Psychometric Evidence of the Italian Anxiety Sensitivity Index-3 (ASI-3) in Patients with Anxiety Disorders and Psychosis. Research in Psychology and Behavioral Sciences, 3(1), 7-17. http://doi.org/10.12691/rpbs-3-1-3

Reiss, S. (1987). Theoretical perspectives on the fear of anxiety. Clinical Psychology Review, 7(6), 585-596. http://doi.org/10.1016/0272-7358(87)90007-9 
Salkovskis, P. M. (1996). The cognitive approach to anxiety: Threat beliefs, safety seeking behaviour, and the special case of health anxiety and obsessions. In P. M. Salkovskis (Ed.), Frontiers of cognitive therapy (pp. 48-74). New York: Guilford Press.

Salkovskis, P. M., \& Warwick, H. M. C. (1986). Morbid preoccupations, health anxiety and reassurance: a cognitive-behavioural approach to hypochondriasis. Behaviour Research and Therapy, 24(5), 597-602. http://doi.org/10.1016/0005-7967(86)90041-0

Salkovskis, P. M., \& Warwick, H. M. C. (2001). Making sense of hypochondriasis: a cognitive model of health anxiety. In G. J. G. Asmundson, S. Taylor, \& B. J. Cox (Eds.), Health anxiety: Clinical and Research Perspectives on Hypochondriasis and Related Disorders (pp. 46-64). London, UK: John Wiley and Sons Ltd.

Sexton, K., Norton, P., Walker, J., \& Norton, G. R. (2003). Hierarchical Model of Generalized and Specific Vulnerabilities in Anxiety. Cognitive Behaviour Therapy, 32(2), 82-94. http://doi.org/10.1080/16506070302321

Sherrington, C. S. (1948). The integrative action of the nervous system. Cambridge, UK: Cambridge University Press.

Starcevic, V. (2014). Should we deplore the disappearance of hypochondriasis from DSM-5? The Australian and New Zealand Journal of Psychiatry, 48(4), 373-374. http://doi:

\section{$10.1177 / 0004867413515058$}

Tabachnick, B. G., \& Fidell, L. S. (2013). Using Multivariate Statistics, 6th Edition. Boston, MA: Pearson Education.

Taylor, S., \& Asmundson, G. J. G. (2004). Treating health anxiety : a cognitive-behavioral approach. New York: Guilford Press.

Taylor, S., Zvolensky, M. J., Cox, B. J., Deacon, B., Heimberg, R. G., Ledley, D. R., .. Cardenas, S. J. (2007). Robust dimensions of anxiety sensitivity: development and initial validation of the Anxiety Sensitivity Index-3. Psychological Assessment, 19(2), 176-188. http://doi.org/10.1037/1040-3590.19.2.176 
Warwick, H. M. C., \& Salkovskis, P. M. (1990). Hypochondriasis. Behaviour Research and Therapy, 28(2), 105-117. http://doi.org/10.1016/0005-7967(90)90023-C

Watt, M. C., \& Stewart, S. H. (2000). Anxiety sensitivity mediates the relationships between childhood learning experiences and elevated hypochondriacal concerns in young adulthood. Journal of Psychosomatic Research, 49(2), 107-18. http://doi.org/http://dx.doi.org/10.1016/S0022-3999(00)00097-0

Wells, A. (2004). A cognitive model of GAD: metacognitions and pathological worry. In Generalized anxiety disorder: Advances in research and practice (pp. 164-186). New York, NY: Guilford Press.

Wells, A. (2009). Metacognitive therapy for anxiety and depression. New York, NY: Guilford Press.

Wells, A., \& Matthews, G. (1994). Attention and emotion : a clinical perspective. Hove, UK: Lawrence Earlbaum Associates.

Wells, A., \& Matthews, G. (1996). Modelling cognition in emotional disorder: The S-REF model. Behaviour Research and Therapy, 34(11), 881-888. http://doi.org/10.1016/S00057967(96)00050-2.

Williams, P. G. (2004). The psychopathology of self-assessed health: A cognitive approach to health anxiety and hypochondriasis [Special Issue: Cognition, Emotion, \& Illness]. Cognitive Therapy \& Research, 28, 629-644. 